\title{
Cardiff Depression Study
}

\section{A sib-pair study of life events and familiality in major depression}

\author{
ANNE FARMER, TANYA HARRIS, KATE REDMAN, STEPHANIE SADLER, \\ ARSHAD MAHMOOD and PETER MCGUFFIN
}

\begin{abstract}
Background An excess of both depression and undesirable life events in first-degree relatives of probands with depression as compared with controls has been reported. This association may have reflected a familial factor in common.
\end{abstract}

\begin{abstract}
Aims To examine the familiality of life events and depression and whether there may be a common familial factor influencing vulnerability to depression and the experiencing of life events.

Method In a sib-pair design, 108 probands with depression and their siblings were compared with 105 healthy controls and their siblings for psychopathology and life events.
\end{abstract}

Results The lifetime relative risk of depressive disorder in the siblings of depressed subjects as compared with siblings of controls was 9.74, although these groups did not differ in the life events measures. Several categories of events showed significant sibling correlations, but this was due to the same event affecting both members of the pair.

\section{Conclusions Although depressive disorder was strongly familial, the familial effects on life events were largely explained by shared experiences. There was no evidence for a common factor influencing both depression and life events.}

\section{Declaration of interest The study} was funded by a project grant from the WellcomeTrust.
The Camberwell Collaborative Depression Study (CCDS) examined both life events and family history of depression in probands with depression and their first-degree relatives (Bebbington et al, 1988; McGuffin et al, 1988a,b). The results showed that not only was the frequency of reported life events very significantly increased among the relatives of subjects with depression by comparison with controls, but also, that, within families, members, exposure to life events showed only a weak and non-significant association with depression. Subsequently, twin studies have also shown that reporting of life events is familial, and that for some life events there is moderate genetic influence Plomin \& Bergeman, 1991; Thapar \& McGuffin, 1996).

The CCDS researchers suggested that at least part of the association between life events and depression results from familial factors that influence both, such as personality attributes leading to risk-taking behaviour or having high levels of threat perception. In the Cardiff Depression Study, we aimed to investigate this matter further by using a sib-pair design to compare psychopathology, life events, measures of personality and attributional and cognitive style. In this paper we report the findings on co-familiality of depression and life events.

\section{METHOD}

\section{Subject recruitment}

The probands selected were aged 18-65 years, fulfilled ICD-10 (World Health Organisation, 1993) operational criteria for moderately severe or severe unipolar depression and had a sibling who was willing to be studied. Weekly reviews of the medical records of all admissions to the in-patient and day units of two hospitals, 11 out-patient clinics and one community mental health team (CMHT) in Cardiff and day hospitals and CMHTs in south
Gwent were undertaken by two specialist registrars in psychiatry (S.S. and A.M) between September 1995 and May 1998 in order to find potential respondents. Those whose medical records indicated that they may fulfil the inclusion criteria were approached personally regarding participation. Subjects whose case record or subsequent interview showed evidence of current or prior history of psychotic, melancholic or bipolar symptoms were excluded, as were subjects who did not have a sibling willing to participate.

In addition, probands with depression were recruited from two general practices in Cardiff. One of the psychiatrists (S.S) obtained listings from each practice of all patients currently receiving repeat prescriptions for antidepressant medication. All such patients were then approached personally (by phone or by calling at their home) in order to assess their willingness to participate and to assess whether they fulfilled the inclusion criteria. Where possible, the sibling nearest in age to the depressed proband was studied; where this was not possible, the sibling next in age was invited to participate.

An age- and gender-matched sample of control subjects was recruited from two sources: firstly from patients attending orthopaedic and dental out-patient clinics, and secondly from employees of the University Hospital of Wales Trust, who were invited to participate via a request in their wage or salary slips. Orthopaedic and dental out-patient clinic attenders were initially screened with the 30-item General Health Questionnaire (GHQ; Goldberg, 1978). Those who scored below the 'caseness' threshold (i.e. less than 11) on this questionnaire were personally approached by one of the research psychologists (T.H. or K.R.). Those respondents who had no history of depression and who had a sibling who was willing to be studied were recruited as control probands. Similarly, Trust employees who responded to our request were interviewed by telephone by T.H. or K.R. in order to establish whether they had ever been treated for depression and whether they had a sibling who was willing to be studied. As with the depressed siblings, where possible their siblings nearest in age were recruited; otherwise, the sibling next in age was invited to participate.

\section{Interviews and self-rating questionnaires}

All subjects were interviewed personally. In the majority of cases the interview was face 
to face but 20 depressed $(18.5 \%)$ and 35 control siblings $(33.3 \%)$ were interviewed by telephone. Interviewers used the Schedules for the Clinical assessment of Neuropsychiatry (version 2) (SCAN; Wing et al, 1990) and the Life Events and Difficulties Schedule (LEDS; Brown \& Harris, 1978). By careful enquiry at interview, supplemented by examination of the case records where available, the date of onset of illness was agreed with the probands with depression. Where the proband was chronically ill and onset of the illness could not be determined (a few cases only), events were rated for the 12 months prior to interview. In order that life events would be recorded for the same period across sibling pairs, events and difficulties of depressed probands for siblings were recorded for 12 months before the proband's illness onset, unless the sibling was also currently ill, in which case the date of illness onset was determined in the same way as for the depressed probands. For control probands and their siblings, enquiry was made for the 12 months before interview date.

Events and difficulties were recorded according to the LEDS instruction manual and panel-rated in the standard way for contextual severity on a four-point scale and for independence. All subjects also completed self-report questionnaires in order to evaluate risk-taking behaviour and threat perception.

\section{Proband and sibling characteristics}

Initially, 119 depressed probands and their siblings and 148 control probands and their siblings were recruited. Information was incomplete for one or both members of the pairs in 11 of the depressed group and 22 of the control group. Hence, complete information was obtained for 108 probands with depression (38 males and 70 females) and their siblings (33 males and $75 \mathrm{fe}$ males), and for 126 control probands (44 males and 82 females) and their siblings (50 males and 76 females). Because there was a significant age difference between the proband with depression and the control proband which could potentially confound the findings for both life events and depressive symptoms, the 21 youngest control pairs were omitted from the data set for the present analyses. Hence, the final analyses were carried out on 108 depressed proband-and-sibling pairs and 105 control proband-and-sibling pairs (control probands: 27 male and 78 females, control siblings: 42 males and 63 females).

\section{Statistical analyses}

SPSS Version 8 for Windows (SPSS Inc, 1998) was used to create a database and to undertake the statistical analyses.

\section{RESULTS}

\section{Demographic features}

The genders, occupational statuses and mean ages at the time of interview for the four groups of respondents are shown in Table 1. There were no significant differences in the gender distribution among the four groups $\left(\chi^{2}=5.38\right.$, d.f. $=3$, NS) and, as expected having matched the probands for age, there was no significant age difference across the groups (Kruskal-Wallis $\chi^{2}=1.13$, d.f. $=3$, NS). Only $52 \%$ of the probands with depression were in paid employment, compared with over $70 \%$ of the other respondents. Thirty-nine per cent of the male and $26 \%$ of the female probands with depression were classed as 'disabled'. Only $4 \%$ of all respondents were unemployed or had never worked. Marital status, defined as 'living with a partner' (married or cohabiting) or 'living alone' (single, divorced, widowed or separated), showed no significant differences between probands with depression and control probands $\left(\chi^{2}=0.56\right.$, d.f. $=1$, NS). However, the siblings of depressed probands were significantly more likely to be living with a partner than the probands with depression themselves $\left(\chi^{2}=13.74 \quad\right.$ d.f. $=1$, $P<0.001)$ or than the siblings of control probands $\left(\chi^{2}=14.66\right.$, d.f. $\left.=1, P<0.001\right)$. Probands with depression recruited from primary care were significantly younger than those recruited from hospital in-patient and out-patient services mean ages: inpatients with depression -60 years; outpatients with depression -60 years; primary care patients -35 years) (KruskalWallis $\chi^{2}=11.5$, d.f. $\left.=2, P=0.003\right)$.

Twenty-four $(23 \%)$ of the control probands were recruited via out-patient clinics (all but one came from orthopaedic clinics), while $81(77 \%)$ responded to the request for volunteers. It is possible that control probands recruited via the orthopaedic clinics were more hazard-probe than respondents recruited from other sources. However, those recruited from these clinics reported no more life events than those recruited from elsewhere (Mann-Whitney $U$-test: $z=-0.41, \mathrm{NS})$.

Fewer probands with depression than control probands were able to recruit their nearest-age sibling $\left(\chi^{2}=4.90, \quad\right.$ d.f. $=1$, $P=0.03$ ).

\section{Depression ratings}

The data from the SCAN interviews were scored using the CATEGO-5 program (Wing et al, 1990). The CATEGO-5 program produces ICD-10 operational definitions for unipolar depression as well as an Index of Definition severity rating. All depression probands fulfilled one of the following ICD-10 categories: F32.1 (moderate depressive episode), F32.2 (severe depressive episode without psychotic symptoms), F33.1 (recurrent depressive disorder - current episode moderate) or F33.2 (recurrent depressive disorder - current episode severe without psychotic symptoms). All depressed probands had Index of Definition levels of 5 or 6, which confirmed that all reached 'caseness' levels of illness severity. Thirty-six probands with depression $(33.3 \%)$ were experiencing a first episode of depression, while 72 $(66.7 \%)$ were having a recurrent episode. The mean age of probands with depression experiencing their first episode of illness was 37.8 years, compared with 40.3 years for those experiencing a recurrent episode, although these differences were not statistically significant (Mann-Whitney $U$-test. $z=1.12$, NS).

Table 2 shows the prevalence of CATEGO-5-derived ICD-10-defined unipolar depression in the siblings. Nine $(7.4 \%)$ of probands with depression reported being treated for an episode of depression at the time of interview; all of these siblings were classified as 'cases' by CATEGO-5. Twenty $(18.5 \%)$ of the siblings of depressed probands (17 female and three males) who had reported being treated for depression in the past were also classified as 'lifetime ever' cases according to CATEGO-5, as were two (1.9\%) (both females) of the siblings of control probands $\lambda=9.7$ (95\% CI 2.34-40.01). This difference was highly significant $\left(\chi^{2}=15.87\right.$, d.f. $=1, P<0.001$ ).

\section{Life events ratings}

Number of contextual life events

The mean numbers of severe (threat contextually rated as 1 or 2 on the LEDS) 
Table I Gender, mean age and occupational status of the four respondent groups

\begin{tabular}{|c|c|c|c|c|c|c|}
\hline \multirow[b]{2}{*}{ Sample } & \multirow[b]{2}{*}{$n$} & \multirow[b]{2}{*}{$\begin{array}{c}\text { Mean (s.d.) ages } \\
\text { (years) }\end{array}$} & \multirow[b]{2}{*}{$\begin{array}{c}\text { Percentage in paid } \\
\text { employment }\end{array}$} & \multicolumn{3}{|c|}{ Percentage full time } \\
\hline & & & & Percentage disabled & $\begin{array}{l}\text { at home, } \\
\text { retired or student }\end{array}$ & $\begin{array}{c}\text { Percentage unemployed } \\
\text { or never employed }\end{array}$ \\
\hline \multicolumn{7}{|c|}{ Depressed probands } \\
\hline Male & 38 & $41.6(10.4)$ & $50 \%$ & $39 \%$ & $9 \%$ & $3 \%$ \\
\hline Female & 70 & $38.8(10.8)$ & $53 \%$ & $26 \%$ & $15 \%$ & $6 \%$ \\
\hline \multicolumn{7}{|c|}{ Siblings of depressed probands } \\
\hline Male & 33 & $38.8(10.8)$ & $82 \%$ & $6 \%$ & $9 \%$ & $3 \%$ \\
\hline Female & 75 & $37.9(10.7)$ & $71 \%$ & $3 \%$ & $17 \%$ & $9 \%$ \\
\hline \multicolumn{7}{|c|}{ Control probands } \\
\hline Male & 27 & $41.0(12.0)$ & $74 \%$ & $7 \%$ & $19 \%$ & $0 \%$ \\
\hline Female & 78 & $36.2(12.4)$ & $87 \%$ & $1 \%$ & $10 \%$ & $1 \%$ \\
\hline Male & 42 & $36.2(12.4)$ & $83 \%$ & $0 \%$ & $14 \%$ & $2 \%$ \\
\hline Female & 63 & $4 I .1$ (II.7) & $81 \%$ & $2 \%$ & $18 \%$ & $0 \%$ \\
\hline
\end{tabular}

Table 2 Prevalence of CATEGO-5-derived ICD-10 unipolar depression in siblings

\begin{tabular}{lccc}
\hline Proband type & $n$ & $\begin{array}{c}\text { Percentage currently } \\
\text { depressed }\end{array}$ & $\begin{array}{c}\text { Percentage with lifetime } \\
\text { ever depression }\end{array}$ \\
\hline Depressed & 108 & $7.4 \%$ & $18.5 \%$ \\
Control & 105 & $0 \%$ & $1.9 \%$ \\
\hline
\end{tabular}

Table 3 Mean number of severe threatening contextually rated life events

\begin{tabular}{lccc}
\hline & $n$ & $\begin{array}{c}\text { Mean number (s.e.) of } \\
\text { life events at I2 months }\end{array}$ & $\begin{array}{c}\text { Mean number (s.e.) of } \\
\text { life events at 3 months }\end{array}$ \\
\hline $\begin{array}{l}\text { Depressed probands } \\
\text { Siblings of depressed } \\
\text { probands }\end{array}$ & 108 & $1.04(0.44)^{*}$ & $0.45(0.07)^{*}$ \\
$\begin{array}{l}\text { Cintrol probands } \\
\text { Siblings of control }\end{array}$ & 108 & $0.52(0.09)$ & $0.17(0.05)$ \\
probands & 105 & $0.36(0.06)$ & $0.10(0.03)$ \\
\hline
\end{tabular}

$* P=0.000$.

life events for all four groups are for three and 12 months are shown in Table 3. Probands with depression experienced very significantly more such events for both time frames than the other three groups (three months KruskalWallis $\chi^{2}=30.05$, d.f. $=3, P<0.001,12$ months: Kruskal-Wallis $\chi^{2}=21.59$, d.f. $=3$, $P<0.001$ ). Siblings of probands with depression had only a modestly elevated frequency of events compared with siblings of control probands; the difference was not significant at either three or 12 months (Mann-Whitney $U$-test: $z=-0.67$ and $z=-0.82$ respectively).

\section{Severe independent and possibly independent} events

There were significant differences in the mean number of severe independent or possibly independent life events (Table 4) between depressed and control probands at three months (Mann-Whitney $U$-test: $z=1.88, P=0.03$ ) but not at 12 months (Mann-Whitney $U$-test: $z=-0.92$ ). Again, although the siblings of probands with depression had more frequent events than control siblings, the differences at three months (Mann-Whitney $U$-test: $z=-0.22$ ) and 12 months (Mann-Whitney $U$-test: $z=-0.91)$ were not significant. Probands with depression who were having their first episode of illness had significantly more independent and possibly independent severe events than probands who had experienced a previous episode (three months, Mann-Whitney $U$-test: $z=-3.40, P<0.001$; 12 months Mann-Whitney $U$-test: $z=-3.05$, $P=0.001$ ).

For comparison with the CCDS, severe life events that were judged to be independent or possibly independent were dichotomised into whether one or more such events were present or absent over a three month and a 12-month period. The results are shown in Table 5. There were no significant differences across the four groups (three months: $\chi^{2}=4.73$, d.f. $=3$ ). In particular, and by contrast with the CCDS, there was no significant difference at three months in the proportion siblings of probands with depression who had experienced events in this category between probands with depression and control siblings $\left(\chi^{2}=0.004\right.$, d.f.=2). Also by contrast with the CCDS, there was an association between recent life events and current depression in the relatives of probands with depression. Of siblings of probands with depression rated as 
Table 4 Mean number of independent and possibly independent severely threatening contextually rated life events

\begin{tabular}{lccc}
\hline & $n$ & $\begin{array}{c}\text { Mean number (s.e.) } \\
\text { of life events at I2 months }\end{array}$ & $\begin{array}{c}\text { Mean number (s.e.) } \\
\text { of life events at 3 months }\end{array}$ \\
\hline $\begin{array}{l}\text { Depressed probands } \\
\text { Siblings of depressed } \\
\text { probands }\end{array}$ & 108 & $0.43(0.08)$ & $0.19(0.05)$ \\
$\begin{array}{l}\text { Control probands } \\
\text { Siblings of control }\end{array}$ & 108 & $0.33(0.07)$ & $0.11(0.03)$ \\
probands & 105 & $0.29(0.05)$ & $0.08(0.03)$ \\
\hline
\end{tabular}

Table 5 Proportion of subjects having any severely threatening, contextually rated, independent or possibly independent life events

\begin{tabular}{lccc}
\hline & & \multicolumn{2}{c}{ Percentage $(95 \% \mathrm{Cl})$ having life events } \\
\cline { 3 - 4 } & $n$ & 12 months & 3 months \\
\hline Depressed probands & 108 & $28.7 \%(20.1-37.3)$ & $15.7 \%(8.8-22.6)$ \\
Siblings of depressed proband & 108 & $26.9 \%(18.5-35.3)$ & $9.3 \%(3.8-14.8)$ \\
Control probands & 105 & $24.8 \%(16.5-33.1)$ & $7.6 \%(2.1-12.7)$ \\
Siblings of control probands & 105 & $19.0 \%(11.5-26.3)$ & $8.5 \%(3.1-13.9)$ \\
\hline
\end{tabular}

current cases of depression, $37.5 \%$ had experienced one or more independent or possibly independent severe events in the three months before interview, compared with $7 \%$ of probands with depression rated as non-cases (Yates $\chi^{2}=4.9$, d.f. $=1, P=0.013$, one-tailed).

\section{Familiality of life events}

There were significant correlations within the total sample of 213 sibling pairs for the number of life events reported for three months (Pearson $r=0.20, P<0.005$ ) and 12 months $(r=0.22, \quad P<0.001)$. However, these correlations were partly explained by shared events that impinged on both members of the pairs. The partial correlations controlling for shared events were $r=0.16$ $(P=0.012)$ at three months and $r=0.13$ at 12 months $(P=0.036)$. In keeping with the CCDS finding that events rated as independent may nevertheless be familial, there was evidence of familiality for severe independent events over 12 months in the total sample of 213 pairs (Spearman $\rho=0.32$, $P<0.001)$. However, this was not confined to the probands with depression and their siblings ( $\rho=0.33, P<0.001$ ), and the correlation was only slightly lower $(\rho=0.31$, $P<0.001$ ) in control probands and their siblings. There was also a modest correlation for severe independent events over three months in the total sample $(\rho=0.19$, $P<0.005)$. However, when shared events were controlled for, both the three-month and 12-month correlations for the total sample reduced to $\rho=0.06$, which was not significant.

\section{DISCUSSION}

\section{Familiality of ICD-I0 unipolar depression}

This study was designed to examine the familial aggregation of depression and life events. In particular we aimed to explore the possibility raised by McGuffin et al $(1988 b)$ - and supported by a study of twins (Thapar \& McGuffin, 1996) - that at least part of the association between life events and depression in studies of unrelated individuals results from both being familial. We have found strong evidence for familiality of depression as defined by ICD-10. Indeed, the relative risk of disorder in the siblings of subjects with depression compared with the siblings of healthy controls was higher than in most previous studies of unipolar depression (Tsuang $\&$ Faraone, 1990), even if we take into account the large confidence intervals of our estimates. This probably reflects the comparatively low frequency of depression in the control siblings and the ascertainment via control probands who were screened for mental health.

\section{Differences between the Cardiff and Camberwell studies}

Using the same design might be expected to amplify differences between the relatives of depressed subjects and control relatives with respect to threatening life events. In fact, we failed to find any convincing evidence of higher rates of life events in the siblings of probands with depression than in the control siblings. It is unlikely that this finding could be explained by lack of power. The CCDS results, where 70 of 244 relatives of probands with depression experienced severe events over a three-month period compared with 21 of 289 controls gave an odds ratio of 5.13 (95\% CI 3.04$8.66)$. We estimate that our power to detect such an odds ratio at $\alpha=0.05$ is over $99 \%$, and that even if the true odds ratio were only 3.04 the power would still be approximately $80 \%$.

How then can we explain the differences between the present study and the CCDS? One possibility is that they result from the proband with depression samples in the two studies differing in terms of their symptom pattern or severity. The Cardiff study included probands ascertained via general practice and, by contrast with the CCDS (Bebbington et al, 1988), did not include any subjects with an Index of Definition greater than six or any who had psychotic or melancholic subtypes of unipolar depression. However, this fact seems unlikely to explain the differences in the frequency of life events in relatives, because life events are associated with broadly defined depression (Brown \& Harris, 1978) and as much with mild 'neurotic' forms as with more severe 'endogenous' types (Bebbington et al, 1988). An alternative reason is that in restricting ourselves to a study of siblings we have introduced a bias. For example, we were successful in recruiting the nearest-age sibling less often in the depression sample than in the control sample. The siblings of probands with depression were also more likely to be cohabiting in a stable relationship.

There is therefore a possibility that, by contact with a study including all firstdegree relatives our sib-pair design tended to preferentially recruit stable, socially compliant individuals. Even so, this did 
not prevent us from finding a large difference in depression between the two sibling samples, and would therefore not seem to offer a convincing explanation of the failure to detect differences in life events.

A more likely explanation of differences between the two studies is that the CCDS focused on probands with clearly defined recent onsets of depression, whereas the Cardiff study did not. Hence, although the Cardiff depression probands showed a high number of recent severe life events, this number was not large enough to produce a significant excess compared with controls when life events were dichotomised into present or absent over a three-month period. The CCDS depressed-proband sample showed a much higher rate of adverse experiences, with a 'provoking agent' occurring in almost half of the sample (Bebbington et al, 1988). The possibility arises that a study such as the CCDS focusing on 'onset cases' and finding a strong association between depression and threatening events in probands tends to identify a coincident period of turmoil affecting other members of the family. In the CCDS an attempt was made to control for this by excluding 'proband-related' events from the family analysis. However, the time course of life events in the CCDS (McGuffin et al, 1988b) would support a 'family turmoil' explanation, because the excess of events occurred mainly in the three-month period before interview.

Another methodological difference between the Cardiff and Camberwell studies is the time period used for rating events in the siblings of probands with depression, which was determined by the timing of illness onset in the depressed probands in the Cardiff Study. Comparable time frames were selected in the depressed proband-sibling pairs in order to allow the familiality of events to be assessed. Hence, enquiry regarding life events was some distance back in time for some of the probands with depression and their siblings. Recall failure could have led to lower rates of events being reported in these respondents and could account for the nonsignificant difference between the groups for independent events present or absent over three and 12 months.

\section{Familiality of life events and comparison with other studies}

The present study found evidence of familiality of life events across the whole sample,

\section{CLINICAL IMPLICATIONS}

There is strong evidence for familiality of ICD-10 unipolar depression.

- There is no evidence for excess life events in siblings of probands with depression compared with siblings of healthy controls.

Familiality for severe events in both depressed and control sibling pairs at three and 12 months disappeared when events shared by both siblings were removed from the analysis.

\section{LIMITATIONS}

- The sib-pair design did not allow a strictly systematic method of ascertainment of depressed and control probands.

- The same interviewers carried out the interviews for both the Life Events and Difficulties Schedule and the Schedules for the Clinical Assessment of Neuropsychiatry.

Failure to recruit the sibling nearest in age for probands with depression may have selected such siblings for health.

ANNE FARMER, FRCPsych, Social, Genetic and Developmental Psychiatry Research Centre, Institute of Psychiatry, Denmark Hill, London; TANYA HARRIS, MSc, KATE REDMAN, BA, STEPHANIE SADLER, MRCPsych, ARSHAD MAHMOOD, Department of Psychological Medicine, University of Wales College of Medicine, Cardiff; MRCPsych, PETER McGUFFIN, FRCPsych, Social, Genetic and Developmental Psychiatry Research Centre, Institute of Psychiatry, Denmark Hill, London

Correspondence: Dr Anne Farmer, Social, Genetic and Developmental Psychiatry Research Centre, Institute of Psychiatry, London

(First received 26 February 1999, final revision 29 June 1999, accepted 30 June 1999)

as reflected in significant positive correlations for total number of events and for severe independent events. In keeping with recent twin studies which have sought to identify events that impinge upon both members of a pair (Kendler et al, 1993; Thapar \& McGuffin, 1996), we rated events according to whether they were shared by the probands and their siblings. When we controlled for shared events the partial correlations for total number of events were reduced, while for severe independent events the partial correlations were not significantly different from zero, indicating that the entire familial effect was explained by events being shared.

\section{Limitations of the present study}

One of the main limitations of the Cardiff study was that there was not a strictly systematic method of ascertainment of the probands. It was not possible to have separate interviewers carry out the LEDS and SCAN interviews or even to ensure that siblings were assessed blind to proband diagnosis. Although such lack of blindness could have resulted in an exaggerated familial effect on the diagnosis of depression, this effect might in part have been counterbalanced by the fact that we were able to interview nearest-age siblings less often among siblings of depressed probands than among control siblings. This is unlikely to account completely for the lack of an excess of adverse events in that sample - and again, lack of blindness might have been expected to bias in favour of finding such an effect.

In conclusion, we did not replicate the most striking finding of the CCDS - that severe events judged to be independent or 
possibly independent of the subjects' actions are familial - once we allowed for events that impinge on both members of sibling pairs. Our present findings therefore provide no support for the hypothesis that there is a causal factor in common between depressive disorder and severe life events.

\section{REFERENCES}

Bebbington, P. E., Bruagha, T., McCarthy, B., et al (1988) The Camberwell Collaborative Depression

Study: I. Depressed probands: adversity and the form of depression. British Journal of Psychiatry, I52, 754-765.
Brown, G.W. \& Harris, T. O. (1978) Social Origins of Depression: A Study of Psychiatric Disorder in Women. New York: Free Press.

Goldberg, D. (1978) General Health Questionnaire. Windsor: NFER - Nelson.

Kendler, K. S., Neale, M. C., Kessler, R. C., et al (1993) A twin study of recent life events and difficulties. Archives of General Psychiatry, 50, 789-796.

McGuffin, P., Katz, R., Aldrich, J., et al (1988a)

The Camberwell Collaborative Depression Study:

II. The investigation of family members. British Journal of Psychiatry, 152, 766-774.

\& Bebbington, P. E., (1988b) The

Camberwell Collaborative Depression Study III. Depression and adversity in the relatives of depressed probands. British Journal of Psychiatry, 152. 775-782.
Plomin, R. \& Bergeman, C. S. (1991) The nature of nurture: genetic influence on 'environmental' measures. Behavior and brain Science, 14, 373-427.

SPSS Inc (1998) SPSS for Windows: Base System User's Guide. Release 8.0.2. Chicago, IL: SPSS Inc.

Thapar, A. \& McGuffin, P. (1996) Genetic influences on life events in childhood. Psychological Medicine, 26, 813-820.

Tsuang, M.T. \& Faraone, S.V. (1990) The Genetics of Mood Disorders. Baltimore, MD. Baltimore, MD: Johns Hopkins University Press.

Wing, J. K., Babor, T., Brugha, T., et al (1990)

SCAN: Schedules for the Clinical Assessment of Neuropsychiatry. Archives of General Psychiatry, 47, 589-593.

World Health Organization (1993)

International Classification of Diseases, 10th revision. Diagnostic Criteria for Research. Geneva: WHO. 